\title{
Caffeine is associated with improved alveolarization and angiogenesis in male mice following hyperoxia induced lung injury
}

Vikramaditya Dumpa ${ }^{1}$, Lori Nielsen², Huamei Wang ${ }^{2}$ and Vasantha H. S. Kumar ${ }^{2 *}$ (D)

\begin{abstract}
Background: Caffeine therapy for apnea of prematurity reduces the incidence of bronchopulmonary dysplasia (BPD) in premature neonates. Several mechanisms, including improvement in pulmonary mechanics underly beneficial effects of caffeine in BPD. As vascular development promotes alveologenesis, we hypothesized that caffeine might enhance angiogenesis in the lung, promoting lung growth, thereby attenuating BPD.

Methods: $\mathrm{C} 57 \mathrm{~B} / / 6$ mice litters were randomized within $12 \mathrm{~h}$ of birth to room air (RA) or $95 \% \mathrm{O}_{2}$ to receive caffeine ( $20 \mathrm{mg} / \mathrm{kg} /$ day) or placebo for 4 days and recovered in RA for $12 \mathrm{wks}$. The lung mRNA and protein expression for hypoxia-inducible factors (HIF) and angiogenic genes performed on day 5. Lung morphometry and vascular remodeling assessed on inflation fixed lungs at 12 wks.

Results: Caffeine and hyperoxia in itself upregulate HIF-2a and vascular endothelial growth factor gene expression. Protein expression of HIF-2a and VEGFR1 were higher in hyperoxia/caffeine and angiopoietin-1 lower in hyperoxia. An increase in radial alveolar count, secondary septal count, and septal length with a decrease in mean linear intercept indicate an amelioration of hyperoxic lung injury by caffeine. An increase in vessel surface area and a significant reduction in smooth muscle thickness of the pulmonary arterioles may suggest a beneficial effect of caffeine on vascular remodeling in hyperoxia, especially in male mice.
\end{abstract}

Conclusions: Postnatal caffeine by modulating angiogenic gene expression early in lung development may restore the pulmonary microvasculature and alveolarization in adult lung.

Keywords: Caffeine, Newborn, Mice, VEGF, Hypoxia-inducible factors, Lung, Hyperoxia

\section{Background}

Bronchopulmonary dysplasia (BPD), a form of chronic lung disease is a common cause of morbidity and mortality in extremely premature infants. Multiple factors are implicated in the pathogenesis of BPD including chorioamnionitis, oxygen toxicity, mechanical ventilation, and sepsis [1]. Irrespective of the pathogenesis, impaired alveolarization, and dysregulated angiogenesis are the defining characteristics of BPD [2]. Increased risk for

\footnotetext{
* Correspondence: vkumar3@buffalo.edu

${ }^{2}$ Division of Neonatology, Department of Pediatrics, John R Oishei Children's Hospital, University at Buffalo, 1001 5th Floor Main Street, Buffalo, NY 14203, USA

Full list of author information is available at the end of the article
}

asthma, related respiratory hospitalizations, and poor neuro-developmental outcomes are some of the longterm morbidities associated with BPD [3, 4].

Caffeine therapy in very low birth weight (VLBW) infants decreases BPD [5] and improves survival without neurodevelopmental disability at 18-month follow-up in these infants [6]. However, caffeine had no effect on the primary outcome of death or survival with a severe disability when the children were 5 years of age [7]. Caffeine treatment in premature infants not only reduces apnea of prematurity and recurrent hypoxic episodes in infants [8] but also reduces lung injury and improves respiratory function in children [9].

(c) The Author(s). 2019 Open Access This article is distributed under the terms of the Creative Commons Attribution 4.0 International License (http://creativecommons.org/licenses/by/4.0/) which permits unrestricted use, distribution, and reproduction in any medium, provided you give appropriate credit to the original author(s) and the source, provide a link to the Creative Commons license, and indicate if changes were made. The Creative Commons Public Domain Dedication waiver (http://creativecommons.org/publicdomain/zero/1.0/) applies to the data made available in this article, unless otherwise stated. 
Caffeine is a nonspecific adenosine receptor antagonist. Adenosine is a purine nucleoside-signaling molecule with effects on regulating fibrosis, angiogenesis, and inflammation. Caffeine is thought to modulate TGF- $\beta$ signaling [10], decrease inflammation [11] or attenuate endoplasmic stress [12] in protecting the lung from hyperoxia-induced lung injury $[12,13]$. However, several studies have suggested an adverse role for caffeine in lung development $[10,14]$. Although the molecular mechanisms underlying prevention of BPD with caffeine are uncertain, the potential beneficial effects could include antagonist effects of the adenosine receptor subtypes, $A_{1}, A_{2 a}, A_{2 B}$, and $A_{3}$ [15]. Adenosine promotes angiogenesis and regulates the expression of vascular endothelial growth factor (VEGF) through the adenosine receptors in different cell types $[16,17]$ and the regulation of hypoxia-inducible factor (HIF) pathway $[16,18,19]$. Recent studies suggest that disruption of VEGF function plays a pivotal role in the pathogenesis of BPD [20, 21]. Hypoxia-inducible factor1 regulates the expression of genes encoding vascular development, with VEGF and angiopoietins being the important ones [22, 23]. HIF-1 expression is tightly linked to the oxygen concentration in vivo and hyperoxia or even normoxia in the developing lung rapidly induce HIF degradation and hence, VEGF expression [24]. The effects of caffeine on the developing lung vasculature in premature infants are not determined. A caffeine loading dose of $20 \mathrm{mg} / \mathrm{kg}$ would be approximately equivalent to 14-16 cups of coffee, and the maintenance dose $(5-10 \mathrm{mg} / \mathrm{kg})$ equivalent to $4-8$ cups of coffee in an adult. Given these high doses over prolonged periods, our objective was to study whether caffeine modulates the HIF- $1 \alpha /$ angiogenesis pathway contributing to an improvement in lung alveolarization. Lungs of adult mice exposed to hyperoxia as newborns are simplified and exhibit reduced function much like that observed in children with BPD as infants [25]. We investigate the effects of caffeine administration on angiogenesis and lung morphometry in newborn mice exposed to hyperoxia, a lung injury model similar to BPD in premature infants.

\section{Methods}

The Institution Animal Care and Use Committee of the University at Buffalo (Project \# PED24116N- Current) approved all experimental protocols before the study. Time-dated pregnant $\mathrm{C} 57 \mathrm{Bl} / 6$ mice were acclimatized in the lab animal facility after purchasing from the vendor (Envigo RMS Inc., Indianapolis, IN) before delivery. Dams were observed on the day of expected delivery for delivery of new litters with minimal disturbance. To minimize litter-dependent bias, all pups from different litters were distributed randomly between dams (5-6 pups/ dam) within $12 \mathrm{~h}$ of birth into four groups: hyperoxia- caffeine $(H C)$, room air-caffeine $(R A C)$, hyperoxia-saline $(H S)$ and room air-saline $(R A S)$ groups (3-4 litters/group; Minimum of 18 pups/group). Litters were exposed to hyperoxia $\left(95 \% \mathrm{O}_{2}\right)$ for $96 \mathrm{~h}$ from Day 1 to Day $4(H S / H C)$ or to room air $(R A S / R A C)$ to serve as controls. Oxygen exposures were performed in a large Plexiglas chamber monitored for temperature, oxygen concentration $\left(95 \% \mathrm{O}_{2}\right.$ or $\left.21 \% \mathrm{O}_{2}\right)$, and humidity $(50-60 \%)$. We alternated dams between hyperoxia and room air-exposed litters every $24 \mathrm{~h}$ to prevent maternal oxygen toxicity. Mice in the room air group were subjected to the same environment as the hyperoxia group. All pups were weighed at birth and every day after that. Caffeine citrate $(20 \mathrm{mg} / \mathrm{mL}$; Fresenius Kabi, Lake Zurich, IL) was administered at a dose of $20 \mathrm{mg} / \mathrm{kg} /$ day for mice randomized to the caffeine groups ( $R A C / H C$ groups) or an equivalent volume of normal saline for mice randomized to saline ( $R A S / H S$ groups) by intraperitoneal injection. All doses were administered at the same time (10 AM to Noon) once every $24 \mathrm{~h}$ for four doses. Mice were sacrificed $24 \mathrm{~h}$ after the last treatment of caffeine on postnatal day 5 with an intraperitoneal injection of sodium pentobarbital. Gene expression, protein, and cytokine analysis were performed in mice sacrificed on Day 5 in all the four groups (eight mice/group). In the second part of the experiment, mice recovered in room air following $96 \mathrm{~h}$ of hyperoxia and postnatal caffeine for 12 weeks until sacrifice. Lungs were formalin fixed at 12 weeks in all groups (ten mice/group).

\section{RNA isolation}

RNA was isolated from flash frozen mouse lung using RNeasy mini kit (Qiagen, Valencia, CA) with on-column DNase digestion per manufacturer's protocol. RNA integrity was assessed using the Experion Automated Electrophoresis System (Biorad, Hercules, CA).

\section{Real-time quantitative PCR}

Genes of the hypoxia-inducible factor (HIF) pathway (HIF-1 $\alpha$, HIF- $2 \alpha$, HIF- $3 \alpha$, HIF- $1 \beta$ \& prolyl hydroxylase2 ) and selected genes of the angiogenic pathway (VEGF: vascular endothelial growth factor; VEGFRR1/fLT-1: VEGF receptor; ANG1: angiopoietin-1) were analyzed by real-time quantitative PCR. Total cellular RNA was reverse transcribed using the iScript cDNA synthesis kit (Biorad, Hercules, CA). Reactions without reverse transcriptase were included for individual RNAs as negative controls. Primers for the above genes were purchased from Real Time Primers (Elkins Park, PA) and the most stable reference genes phosphoglycerate kinase 1 and peptidylprolyl isomerase A were chosen from a panel of ten genes using geNorm software (Biogazelle, Belgium). Reactions were run in duplicate in a CFX Connect RealTime PCR detection system (Biorad Lab Inc.) using SYBRGreen to measure DNA amplification. The instrument's 
software was used to calculate the threshold cycle $\left(C_{t}\right)$ values for all the genes on the PCR Array. Fold change in gene expression for pair-wise comparison was processed on the Excel-based PCR Array Data Analysis software (SA Biosciences, MD) using the eq. $2^{-\Delta \Delta \mathrm{Ct}}$ by comparing the control group (RAS) to the other three groups (RAC, HS, HC).

\section{Angiogenic protein analysis}

Snap-frozen lung tissue was homogenized in ice-cold PBS ( $\mathrm{pH}$ - 7.4) with protease inhibitors (Sigma, St. Louis, MO), spun, and the supernatant used for protein analysis by ELISA. The protein concentration was determined using the DC protein assay (BioRad, Hercules, CA). Protein analysis for HIF $1 \alpha$, HIF $2 \alpha$ and HIF3 $\alpha$ proteins (NovaTein Biosciences, Woburn, MA) and VEGF, VEGFR1 and ANG1 protein (R\&D Systems, Minneapolis, $\mathrm{MN}$ ) were performed by enzyme-linked immunosorbent assay (ELISA) according to manufacturer's protocol.

\section{Cytokine measurements}

Tumor necrosis factor $\alpha$ (TNF- $\alpha$ ), Interferon $\gamma$ (INF- $\gamma)$ \& interleukin-6 (IL-6) were measured in whole lung homogenates from cell-free supernatants on a postnatal day 5 in all the groups. Cytokine levels performed by ELISA technique (R\&D systems, Minneapolis, MN), were normalized to total lung protein measured by Lowry assay.

\section{Lung histopathology}

The lungs were instilled with $10 \%$ buffered formalin at $25 \mathrm{~cm} \mathrm{H}_{2} \mathrm{O}$ pressure in adult mice following tracheal cannulation. Instilled lungs were fixed overnight, serially dehydrated in ethanol and embedded in paraffin. Lung tissue cut into $5 \mu \mathrm{m}$ full sections and stained with hematoxylin \& eosin. We analyzed five slides/mouse and randomly analyzed 20 fields/slide for lung morphometry in all the groups. Alveolar development was evaluated by assessment of radial alveolar count (RAC) [26] and mean linear intercept (MLI) [27] by Aperio image analysis software (Leica Biosystems Inc., Buffalo Grove, IL). Assessment of secondary septal crest density performed by counting of secondary septae longer than $5 \mu \mathrm{m}$ in highresolution images $\left(\times 400,57,600 \mu \mathrm{m}^{2}\right) ; 20 \mathrm{HPF}$ images assessed per slide and averaged for each animal to calculate the mean for each group [28, 29]. Similarly, elastin stained lung sections were evaluated for mean septal length in high-resolution images $(\mathrm{x} 400 \mathrm{x})$; the septal length was assessed from the base to the tip of the septum; $20 \mathrm{HPF} /$ slide) by Aperio imaging software (Leica Biosystems Inc., Buffalo Grove, IL) [28].

\section{Assessment of lung vessels}

Lung vasculature was assessed on lung sections stained for collagen (trichrome staining) and endothelial cells
(Von Willebrand factor immune histo-chemistry) at 12 wks. Vessels that accompanied the airways were characterized as pulmonary arteries. Pulmonary arterioles of $20-100 \mu \mathrm{m}$ in diameter were included and bronchioles excluded for analysis by a single operator blinded to the study groups. The number of blood vessels/high power field $\left(\times 200 ; 237,600 \mu \mathrm{m}^{2}\right)$ were counted successively in 20 HPFs per slide; the total blood vessel area $\left(\mu \mathrm{m}^{2}\right)$ per HPF was also assessed in the same fields (200x) by Aperio image analysis software (Leica Biosystems Inc., IL, USA). Five lung sections were studied for each animal $(n=$ ten pups per group).

\section{Smooth muscle actin (a-SMA) immunohistochemistry}

We first performed antigen retrieval of lung sections with citrate solution followed by blocking of non-specific binding with $10 \%$ goat serum in phosphate buffered saline (PBS). Lung sections incubated overnight with antibody to $\alpha$-SMA (mouse monoclonal antibody, 1:100 dilution; Sigma-Aldrich Co. St Louis, MO) at $4{ }^{\circ} \mathrm{C}$ and rinsed with PBS. The sections were then incubated with peroxidase-labeled rabbit anti-mouse IgG (1:1000) for 30 min at $37^{\circ} \mathrm{C}$, washed with PBS and stained with $3,3^{\prime}$ diaminobenzidine (Sigma-Aldrich Co). Assessment of wall thickness was performed on $\alpha$-SMA stained pulmonary vessels of $20-100 \mu \mathrm{m}$ diameter at 400x magnification in all the four groups. We used Aperio image analysis software (Leica Biosystems Inc., Buffalo Grove, IL) to measure the cross-sectional area of the pulmonary arteriole. The surface area of the vessel wall assessed as a fraction of the total vessel area by the following formula, Area ovw - Area IVw/Area ovw; wherein, OVW - outer vessel wall, representing surface area of the cross-sectioned vessel; IVW - inner vessel wall, serving the surface area of the vessel lumen) [30].

\section{Statistical analysis}

Replicated 2- $-\Delta \Delta^{\mathrm{C}(\mathrm{t})}$ values for each gene in the control group and the treatment group was used to calculate $p$ values by student's t-test. More than two group comparisons performed by analysis of variance (ANOVA) with Fisher's post-hoc analysis when appropriate (Stat view, Abacus Concepts, Piscataway, NJ). Repeated measures ANOVA used to assess differences in body weight over time among groups. All values expressed as mean \pm standard deviation (SD) of the mean with $n$ representing the number of animals studied. A $p$ value of $<0.05$ was considered significant.

\section{Results}

Growth

There was no difference in body weight at 12 wks between the two room air groups (RAS: $23.52 \pm 1.86 \mathrm{~g}$ vs. RAC: $24.22 \pm 2.92$ g; Fig. 1a). However, postnatal caffeine 


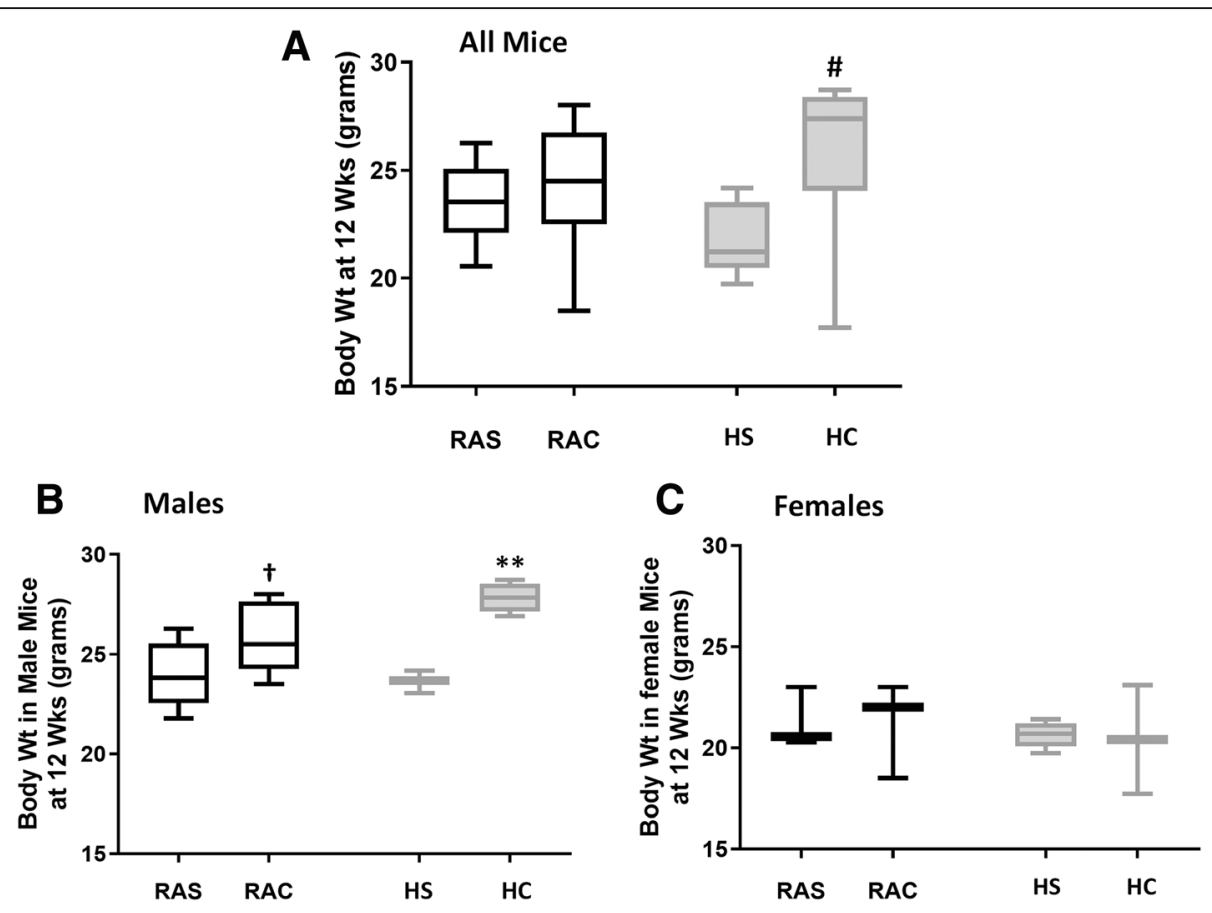

Fig. 1 Body weights (grams) in adult mice at sacrifice in all the four groups (Open box plots - Room air; shaded box plots - hyperoxia; RAS - room air saline; RAC - room air caffeine; HS - hyperoxia saline; HC - hyperoxia caffeine). Caffeine treated mice had significantly higher body weight at 12 wks in hyperoxia (\#p<0.01 vs. HS group, a). Hyperoxic male mice treated with caffeine had significantly higher body weight compared to other groups ( $*^{*} p<0.001$ vs. RAS, RAC \& HS groups, b). Caffeinated male mice had significantly higher body weight compared to RA or hyperoxia controls ( $+p<0.05$ vs. RAS \& HS groups). No significant difference in body weight noted in female mice (c). \# ** + Fisher's post-hoc test, ANOVA ( $n=$ ten mice per group) (RAS - 6 males, 5 females; RAC -6 males, 4 females; HS -5 males, 5 females; HC -6 males, 4 females)

treatment significantly increased body weight in mice exposed to hyperoxia (HS: $21.77 \pm 1.64 \mathrm{~g}$ vs. $H C: 25.99 \pm$ $3.77 \mathrm{~g}, p<0.05$ vs. HS group, ANOVA; Fig. 1a). Male mice gained significant body weight following postnatal caffeine administration. Mice exposed to room air (RA) and treated with caffeine had significantly higher body weight compared to both the saline groups (RAC: $25.79 \pm 1$.ra; $R A S: 23.89 \pm 1.64 \mathrm{~g} \& H S: 23.64 \pm 0.56 \mathrm{~g}$; $p<0.05$ vs. RAS \& HS groups, ANOVA; Fig. 1b). However, in mice exposed to hyperoxia, postnatal caffeine significantly increased body weight compared to all the other three groups (RAS: $23.89 \pm 1.64 \mathrm{~g} ;$ RAC: $25.79 \pm$ $1.75 \mathrm{~g} ; H S: 23.64 \pm 0.56 \mathrm{~g} \& H C: 27.82 \pm 0.82 \mathrm{~g}, p<0.01$ vs. RAS, RAC \& HS groups, ANOVA; Fig. 1b). There was no significant difference in body weight at $12 \mathrm{wks}$ in female mice with or without caffeine (Fig. 1c). We studied ten mice per group (RAS - 6 males, 5 females; $R A C-6$ males, 4 females; $H S-5$ males, 5 females; $H C-6$ males, 4 females).

\section{Gene expression}

Gene expression was measured as fold change (FC) in mRNA expression relative to the control group ( $R A S$ group, FC of $R A S$ group =1, Table 1). Genes involved in the angiogenic pathway such as HIF-2 $\alpha$, PHD-2, and
VEGF were significantly over-expressed in the room air caffeine and hyperoxia-saline groups compared to hyperoxiacaffeine group (Table 1). Expression of ANG-1 was considerably higher in room air mice exposed to caffeine ( $R A C$ group) compared to hyperoxia groups (Table 1). We observed no differences in the expression of HIF- $1 \alpha$, HIF- $3 \alpha$, HIF-1 $\beta$ or Flt-1 (VRGFR1) genes among the three groups.

\section{Angiogenic proteins}

Protein expression in the lung for HIF- $1 \alpha$, HIF- $2 \alpha$, HIF$3 \alpha$, VEGF, FLT-1, and ANG1 was analyzed by enzyme immunoassay in 5-day old mice in all the four groups (Table 2). HIF- $2 \alpha$ protein expression was significantly higher in the hyperoxia-caffeine group ( $p<0.05$ vs. $R A S$ $\mathcal{E} R A C$ groups, Fisher's post-hoc test, ANOVA; Table 2). Expression of VEGF protein was significantly higher in the hyperoxia group compared to the other three groups $(p<0.05$ vs. RAS, RAC \& HC groups, Fisher's post-hoc test, ANOVA; Table 2). Expression of angiogenic receptor, VEGFR1 (FLT-1) protein was significantly higher in the hyperoxia-caffeine group compared to both the room air groups ( $p<0.05$ vs. $R A S \&$ \& $R A C$ groups, Fisher's post-hoc test, ANOVA; Table 2). Expression of ANG-1 protein was significantly lower in the hyperoxia group compared to the other three groups $(p<0.05$ vs. $R A S, R A C \& H C$ 
Table 1 Expression of selected angiogenic genes in the lung by qRT-PCR in newborn mice exposed to hyperoxia $\left(95 \% \mathrm{O}_{2}\right)$ or room air and administered caffeine or saline

\begin{tabular}{llll}
\hline Gene Symbol & Room Air-Caffeine (RAC) Group & Hyperoxia-Saline (HS) Group & Hyperoxia-Caffeine (HC) Group \\
\hline Hif-1a & $2.28 \pm 1.05$ & $2.31 \pm 0.33$ & $2.35 \pm 0.85$ \\
Hif-2a & $2.62 \pm 0.87^{*}$ & $2.67 \pm 0.44^{*}$ & $1.52 \pm 0.70$ \\
Hif-3a & $2.83 \pm 1.25$ & $1.72 \pm 0.44$ & $1.64 \pm 0.71$ \\
Hif-1 $\beta$ & $1.77 \pm 0.34$ & $1.65 \pm 0.20$ & $1.51 \pm 0.43$ \\
PHD-2 & $1.78 \pm 0.30^{*}$ & $1.89 \pm 0.46^{*}$ & $1.00 \pm 0.26$ \\
VEGF & $2.00 \pm 0.42^{*}$ & $3.52 \pm 0.66^{*}$ & $1.17 \pm 0.34$ \\
Flt-1 & $2.71 \pm 0.89$ & $2.44 \pm 0.40$ & $1.93 \pm 0.57$ \\
Ang-1 & $2.85 \pm 1.26^{*}$ & $1.89 \pm 1.11$ & $0.89 \pm 0.27$
\end{tabular}

The fold-change (FC) in gene expression is compared to the room air-saline (RAS) group (control group; FC in RAS $=1.0$. ( $n=8$ pups in each group) Values expressed as fold change \pm SD compared to room air saline group. ${ }^{*} p<0.05$ versus hyperoxia-caffeine group (Fisher's post-hoc test, ANOVA); Hif-1aHypoxia-Inducible Factor-1a; HIF-2a - Hypoxia-Inducible Factor-2a; HIF-3a - Hypoxia-Inducible Factor-3a; Hif-1 $\beta$ - Hypoxia Inducible Factor-1 $\beta$; PHD-2: Prolyl Hydroxylase - 2 (EGLN1); VEGF - Vascular Endothelial Growth Factor; Flt-1: VEGF Receptor 1; Ang-1: Angiopoietin-1. Housekeeping genes - Phosphoglycerate kinase1 (Pgk1); Peptidylprolyl isomerase A (Ppia)

groups, Fisher's post-hoc test, ANOVA; Table 2). There were no differences in protein expression of cytokines, such as TNF- $\alpha$, INF- $\gamma$, and IL- 6 in the lung among the three groups (Table 2).

\section{Histopathology}

Mice exposed to postnatal hyperoxia demonstrate distended alveoli and enlarged air sacs at 12wks of age (Fig. 2e/f) when compared to relatively well-formed alveolar units in the RA groups (Fig. 2: a-d). Radial alveolar count (RAC), a unit of alveolar development was significantly lower in mice exposed to hyperoxia suggesting alveolar simplification (" $p<0.001$ vs. $R A S \&$ $R A C$ groups; Fisher's post-hoc test, ANOVA; Fig. 2i). Mean linear intercept (MLI), a unit of alveolar enlargement was significantly higher in the hyperoxia group (" $p<0.001$ vs. $R A S \& R A C$ groups, Fig. 2j). Postnatal caffeine augmented postnatal alveolarization and attenuated alveolar distension following hyperoxia (" $p<0.001$ vs. HC group, ANOVA; Fig. 2i), suggesting caffeine may ameliorate hyperoxic lung injury in adult mice (Fig. $2 \mathrm{~g} / \mathrm{h}$ ). A significant increase in secondary septal count $(" p<0.001$ vs. $H C$ group, Fisher's post-hoc test, ANOVA; Fig. $3 \mathrm{~m}$ ) and septal length (" $p<0.001$ vs. $H C$ group; Fig. $3 n$ ) further strengthens the protective effects of postnatal caffeine administration. We demonstrate the beneficial effects of caffeine on all markers of alveolar development in both male and female mice (Fig. 2/Fig. 3). The findings advance the protective effects of caffeine against hyperoxia-induced lung injury and promoting lung growth.

Table 2 Protein expression of selected angiogenic proteins and cytokines in the lung measured by enzyme immunoassay (EIA) in newborn mice exposed to hyperoxia $\left(95 \% \mathrm{O}_{2}\right)$ or room air and administered caffeine or saline

\begin{tabular}{|c|c|c|c|c|}
\hline Protein & $\begin{array}{l}\text { Room Air Saline Group } \\
\text { (RAS) }\end{array}$ & $\begin{array}{l}\text { Room Air Caffeine Group } \\
\text { (RAC) }\end{array}$ & $\begin{array}{l}\text { Hyperoxia Saline Group } \\
(\mathrm{HS})\end{array}$ & $\begin{array}{l}\text { Hyperoxia Caffeine Group } \\
(\mathrm{HC})\end{array}$ \\
\hline \multicolumn{5}{|c|}{ HIF \& Angiogenic Proteins (ng or pg/mg protein) } \\
\hline Hif-1a (pg) & $230 \pm 25$ & $215 \pm 41$ & $250 \pm 40$ & $253 \pm 46$ \\
\hline Hif-2a (ng) & $0.232 \pm 0.058$ & $0.117 \pm 0.008$ & $0.274 \pm 0.055$ & $0.464 \pm 0.159^{*}$ \\
\hline Hif-3a (pg) & $6.96 \pm 1.78$ & $5.99 \pm 0.51$ & $7.60 \pm 1.31$ & $6.05 \pm 0.78$ \\
\hline $\operatorname{VEGF}(p g)$ & $55.5 \pm 16.1$ & $64.6 \pm 7.1$ & $177.5 \pm 52.8^{* *}$ & $92.6 \pm 16.4$ \\
\hline Flt-1 (pg) & $2297 \pm 1026$ & $1714 \pm 85$ & $3364 \pm 1590$ & $5866 \pm 3086^{*}$ \\
\hline Ang-1 (ng) & $522 \pm 192$ & $664 \pm 72$ & $258 \pm 70+$ & $455 \pm 70$ \\
\hline \multicolumn{5}{|l|}{ Cytokines } \\
\hline TNF-a (pg/ug protein) & $0.350 \pm 0.01$ & $0.040 \pm 0.01$ & $0.043 \pm 0.02$ & $0.045 \pm 0.01$ \\
\hline INF- $\gamma$ (pg/ug protein) & $0.098 \pm 0.04$ & $0.109 \pm 0.03$ & $0.118 \pm 0.04$ & $0.134 \pm 0.02$ \\
\hline IL-6 (pg/ug protein) & $0.065 \pm 0.02$ & $0.062 \pm 0.01$ & $0.081 \pm 0.04$ & $0.066 \pm 0.01$ \\
\hline
\end{tabular}

HIF \& angiogenic proteins are expressed in $\mathrm{ng}$ or $\mathrm{pg} / \mathrm{mg}$ protein of the lung ( $n=8$ pups in each group)

Values expressed as mean \pm SD. ${ }^{*} p<0.05$ vs RAC \& RAS groups, ** $p<0.05$ vs RAS, RAC \& HC groups, $+p<0.05$ vs RAS, RAC \& HC groups; (Fisher's post-hoc test, ANOVA). HIF-1a - Hypoxia-Inducible Factor-1a; HIF-2a - Hypoxia-Inducible Factor-2a; HIF-3a - Hypoxia-Inducible Factor-3a; VEGF - Vascular Endothelial Growth Factor; Flt-1: VEGF Receptor 1; Ang-1: Angiopoietin-1; TNF-a: tumor necrosis factor alpha; INF- $\gamma$ : interferon gamma; IL-6: interleukin-6. HIF \& angiogenic proteins are expressed as units/mg lung protein 


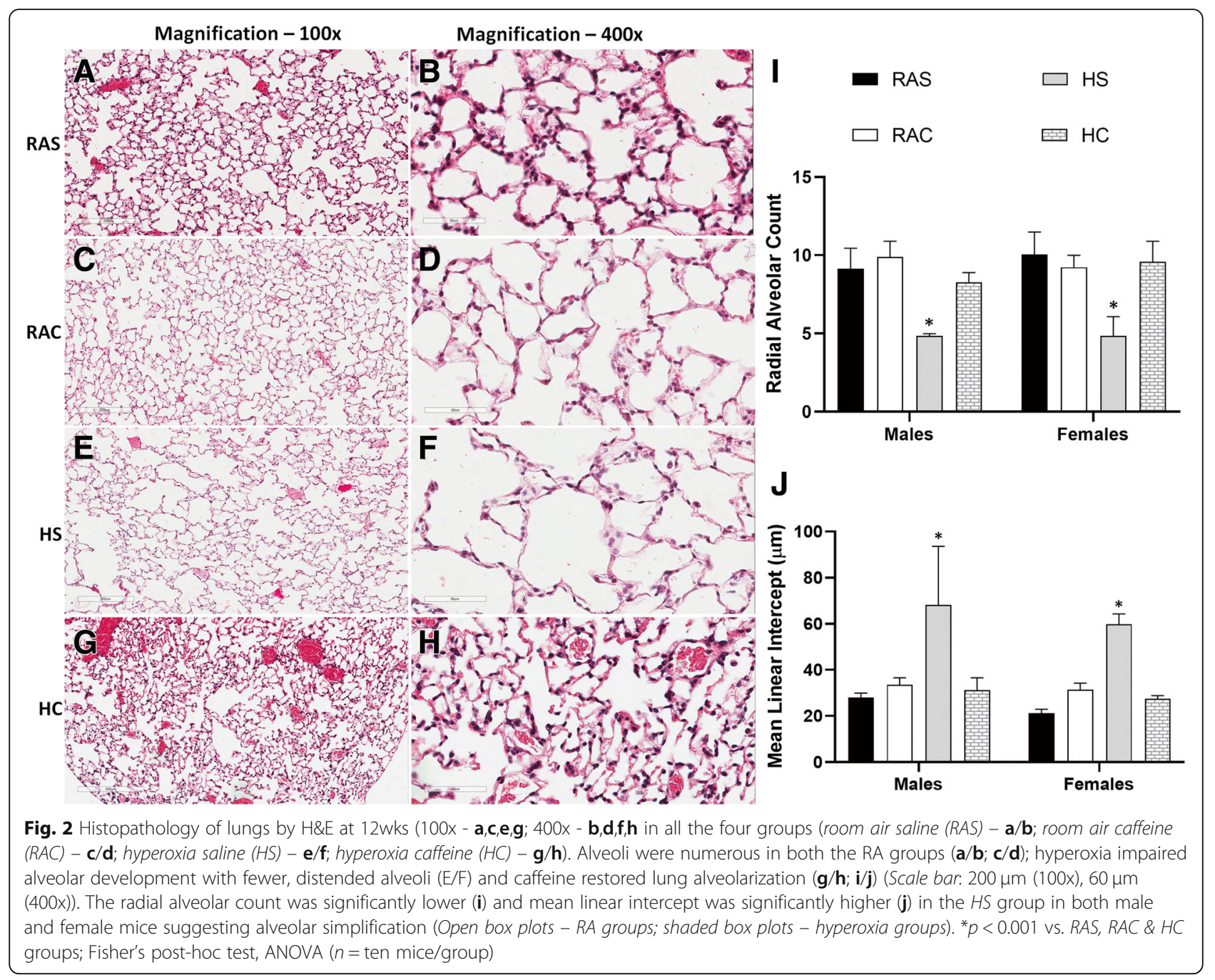

\section{Vessel data}

Pulmonary blood vessels of $20-100 \mu \mathrm{m}$ diameter were counted following von Willebrand factor immunohistochemistry and in trichrome stained lung sections in all the groups (Fig. 3). Blood vessel density expressed as a number of blood vessels per field studied was significantly higher in the hyperoxia group following postnatal caffeine, especially in male mice ( ${ }^{* *} p<0.0001$ vs. $R A S$, $R A C$ and HS groups, Fisher's post-hoc test, ANOVA; Fig. 3o). Control female mice had significantly higher vessel density compared to $R A C$ and $H S$ groups $(+p<$ 0.001 vs. RAC and $H S$ groups, Fisher's post-hoc test, ANOVA; Fig. 3o); however, not different from hyperoxic mice that received postnatal caffeine. The surface area of blood vessels $\left(237,600 \mu \mathrm{m}^{2}\right)$ was significantly higher in both male and female mice that received postnatal caffeine and hyperoxia $(* * 0<0.0001$ vs. $R A S, R A C$ and $H S$ groups, Fisher's post-hoc test, Fig. 3q). The finding suggests that postnatal caffeine promotes microvascular growth along with alveolar growth.
Caffeine \& Pulmonary Arterial Wall Thickness

Assessment of pulmonary vascular smooth muscle thickness was performed in lung sections by $\alpha$-SMA immunohistochemistry in all the groups (Fig. 4). There was no difference in the mean diameter of the pulmonary arterioles analyzed among the groups (RAS: $48.7 \pm 4.0 \mu \mathrm{m} ;$ RAC: $50.2 \pm 2.9 \mu \mathrm{m} ; H S: 48.4 \pm 6.3 \mu \mathrm{m}$; $H C: 51.9 \pm 1.7 \mu \mathrm{m})$. Pulmonary arterioles were thicker with smooth muscle hypertrophy in mice exposed to neonatal hyperoxia group at 12wks (Fig. 4e/f). Postnatal caffeine in mice exposed to hyperoxia significantly reduced vessel wall thickness at $12 \mathrm{wks}$, especially in male mice (" $p<0.001$ vs. RAS \& RAC groups; * $p<$ 0.0001 vs. $H S$ group; Fisher's post-hoc test, ANOVA; Fig. 4i). Arterial wall thickness was not different among the groups in female mice. The effects of caffeine on pulmonary vascular remodeling and consequently on the development of pulmonary hypertension is gender specific with protective and beneficial effects in male mice. 


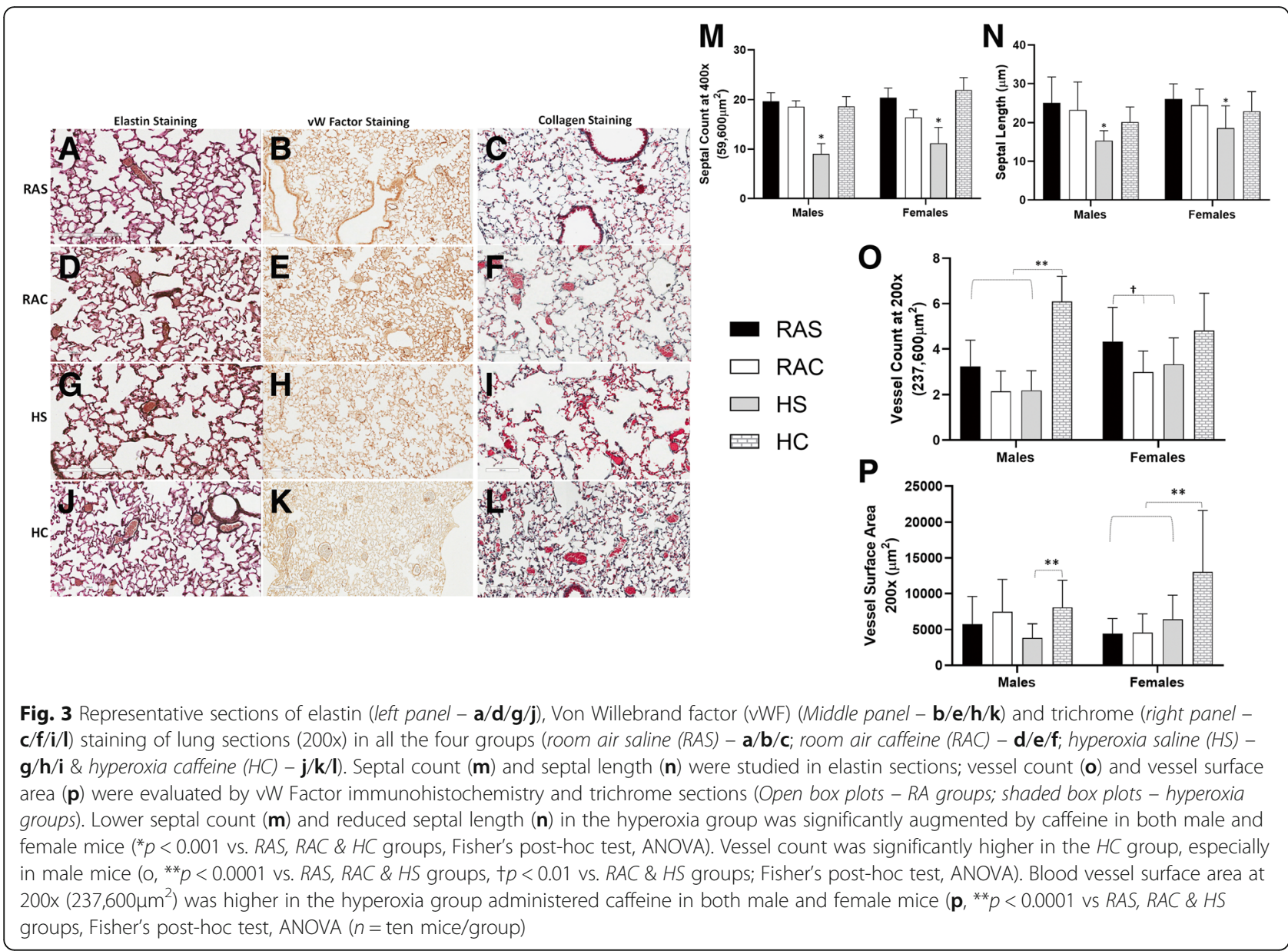

\section{Discussion}

Caffeine therapy for apnea of prematurity reduces the incidence of bronchopulmonary dysplasia in VLBW infants [5]. Although the mechanisms of the possible protective actions of caffeine are not apparent, potential effects on the endothelial cells [31,32] and the vascular smooth muscle [33] in addition to the antagonism of the adenosine receptors [15] partly explain its beneficial effects. We have shown that caffeine by modulating the HIF-angiogenesis pathway, promotes alveolarization and angiogenesis with beneficial effects on the pulmonary vasculature.

Hypoxia-inducible factors (HIFs) are transcription factors that regulate the downstream expression of genes that mediate the response to hypoxia. Constant expression and degradation of HIF by PHD-2 results in not only a steady state concentration but also in a short half-life. In our study, both caffeine and hyperoxia by themselves significantly increased expression of HIF- $2 \alpha$ and angiogenic genes VEGF and ANG-1. Figure 5 illustrates the potential role of caffeine in the modulation and regulation of HIF induced angiogenesis. Reactive oxygen species, including $\mathrm{H}_{2} \mathrm{O}_{2}$, play a significant role in the upregulation of HIF pathway by several mechanisms, including interactions with PHD complex co-factors such as ferrous ion, ascorbate, and succinate [34]. Other intermediates such as nitric oxide, specific microRNAs and transcriptional and post-translational modifications mediate ROS mediated HIF-1 signaling [35]. Studies have shown a paradoxical higher level of HIF-1 $\alpha$ in the presence of hyperoxia [36, 37]. Low concentrations of caffeine actively induce VEGF expression via activation of HIF-1 $\alpha$ [38]. Transcript levels of HIF are of little predictive value concerning protein expression [39], as this can be influenced by protein half-life, post-translational changes, experimental conditions, and by the activity of prolyl hydroxylase isoforms. However, postnatal caffeine significantly induced HIF- $2 \alpha$ protein in the lung in mice exposed to hyperoxia. HIF- $2 \alpha$ could contribute to the expression of angiogenic genes seen in our study.

Angiogenic proteins, VEGF and its receptor, VEGFR1 was higher in both the hyperoxia groups; however, the receptor protein was significantly higher in the hyperoxia-exposed mice that received postnatal caffeine. While some animal studies have reported a relative decrease in lung VEGF mRNA and protein in response to hyperoxia [40-42], 


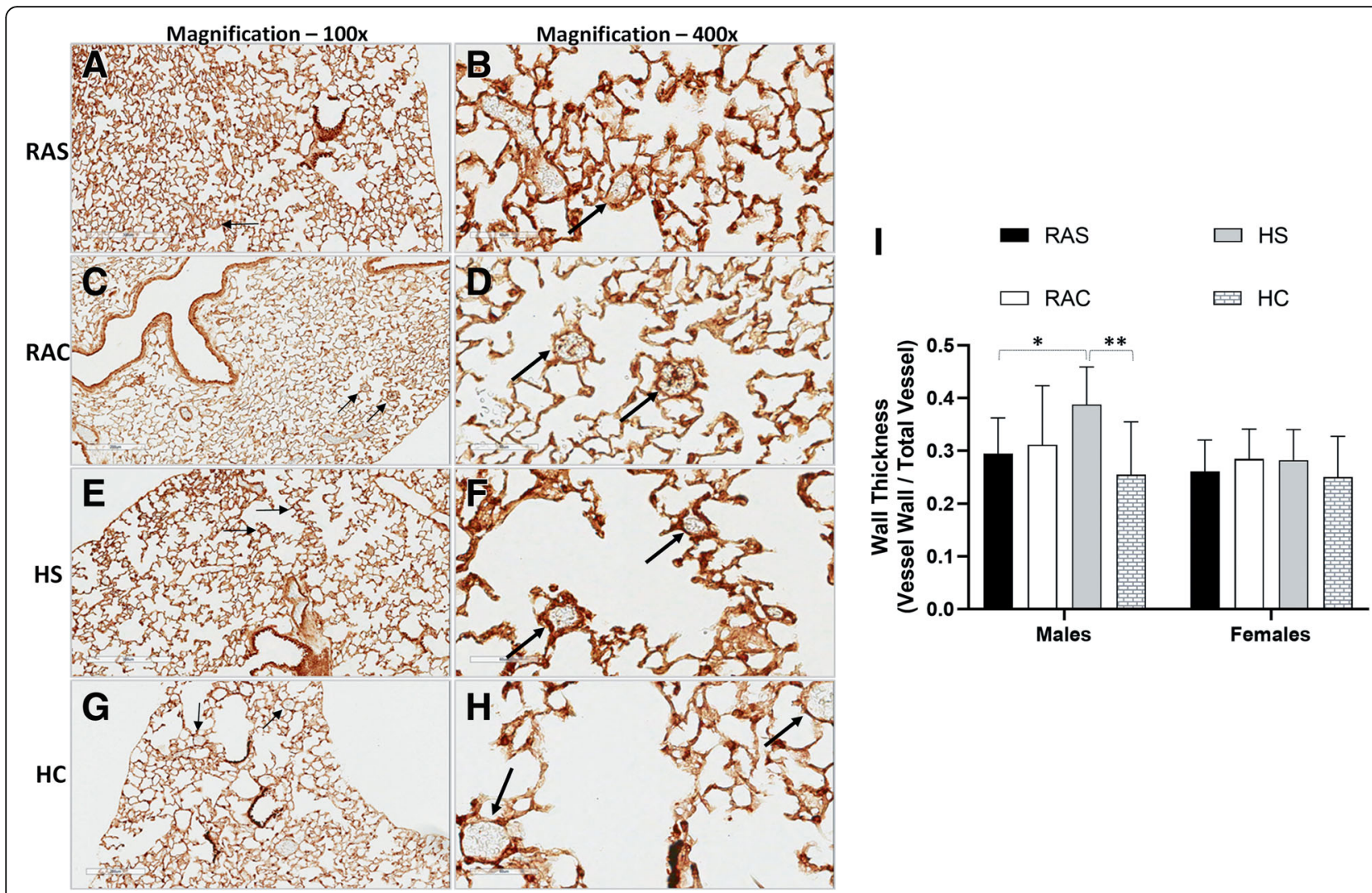

Fig. 4 Assessment of vessel wall thickness at 12wks by a-smooth muscle actin immunohistochemistry of lung sections (100x: a/c/e/g; 400x: b/d/ $\mathbf{f} / \mathbf{h}$; room air saline (RAS): A/B; room air caffeine (RAC): c/d; hyperoxia saline (HS): e/f; hyperoxia caffeine (HC): $\mathbf{g} / \mathbf{h})$. Scale: $200 \mu \mathrm{m}(100 \mathrm{x}), 60 \mu \mathrm{m}$ (400x). Thick arrows (400x) correspond to the same histologic location as thin arrows (100x) of the same group. Demonstrated vessels are of a 30$50 \mathrm{um}$ diameter in all the four groups. Pulmonary arterial vessel wall thickness was greater in the hyperoxia group suggestive of smooth muscle hypertrophy (i; ${ }^{*} p<0.001$ vs. RAS; Fisher's post-hoc test, ANOVA). Caffeine administration attenuated vessel wall thickness, especially in male mice at 12 weeks of age $\left(^{* *} p<0.0001\right.$ vs HS group, Fisher's post-hoc test, ANOVA; i), suggesting it may have beneficial effects on the pulmonary vasculature (Open box plots - RA groups; shaded box plots - hyperoxia groups) ( $n=$ ten mice/group)

others have shown an increase in VEGF protein [43]. The variability in expression may be related to the stage of lung development in an animal model, the timing of the VEGF mRNA and its protein measurement and the variability of the VEGF isoforms measured [44]. The VEGF assay measured both 120 and 164 isoforms, and the expression of both proteins decreases with progression of lung development with low levels in adult lung. Mice in the hyperoxiacaffeine group had higher HIF-2 $\alpha$ protein and VEGFR1 receptor density with relatively normal VEGF protein levels in the lung. Mice exposed to hyperoxia alone had significantly low levels of ANG1, a protein that plays a critical role in mediating reciprocal interactions between the endothelium, surrounding matrix, and the mesenchyme. ANG1 protein enhances the effect of VEGF, contributing to blood vessel maturation and vascular remodeling. Caffeine by increasing ANG1 in the lung may act synergistically with VEGF in ameliorating the abnormal vascular response during the early stages of lung injury. Caffeine by modulating the levels of VEGF and angiopoietin via the HIF pathway not only alters the abnormal vascular responses but may also enhance alveolar and microvascular development in the lung in the presence of hyperoxia.

Vessel density and vessel surface area were higher following postnatal caffeine in hyperoxia-exposed mice. An increase in vasculature may be secondary to higher expression of angiogenic proteins VEGFR1 and ANG1 in the $\mathrm{HC}$ group. An increase in vessel wall thickness following neonatal hyperoxia may suggest developing pulmonary hypertension in the context of hyperoxic lung injury [45]. However, postnatal caffeine attenuated lung injury with a significant decrease in vessel wall thickness following neonatal hyperoxia. The effects of caffeine on vascular remodeling is gender specific, with substantial benefits in male mice. However, female mice that received postnatal caffeine may have had minimal vascular remodeling compared to RA controls. Sex differences in systemic blood pressures are evident in young adults and continue through adulthood, with men more likely to be hypertensive than women regardless of race or 


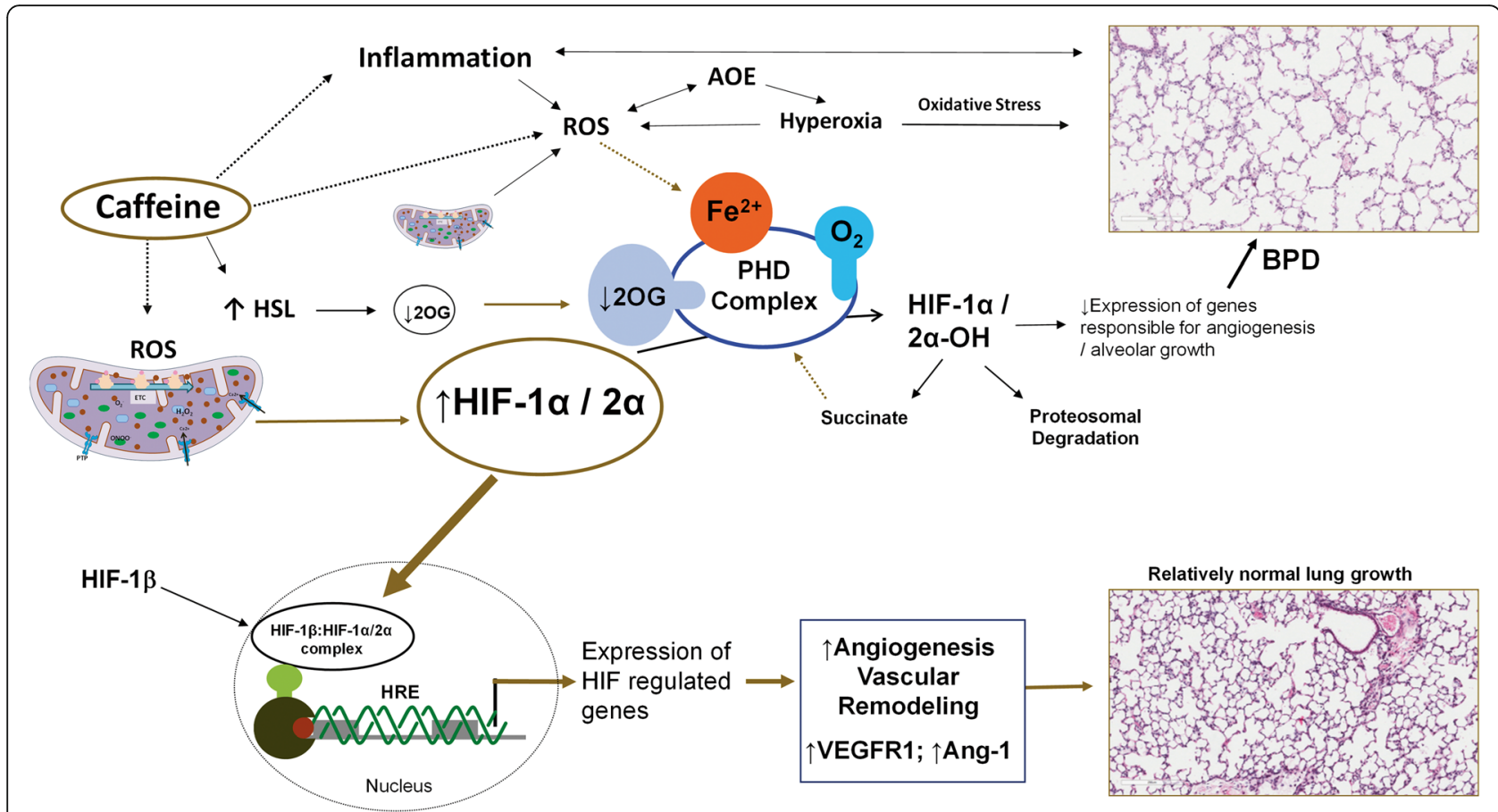

Fig. 5 Illustration of potential modulation of HIF regulation by caffeine. Stabilization of HIF1a/2a determined by several factors including oxygen, the activity of PHD complex and its co-factors and reactive oxygen species. HIF-1a/2a activates multiple genes involved in glycolysis, angiogenesis, vascular remodeling, cell proliferation, and erythropoiesis via nuclear transcription. Higher expression of VEGFR1 and angiopoietin-1 along with vascular remodeling following caffeine administration may normalize lung histology seen in hyperoxia-induced lung injury. Hydroxylation of prolyl hydroxylase complex inactivates HIF-1a/2a followed by ubiquitination and proteasome degradation. HSL: hormone-sensitive lipase; 2OG: 20xyglutarate; ROS: reactive oxygen species; PHD: prolyl hydroxylase; HIF: hypoxia inducible factor; HRE: hypoxia response element; VEGFR1: vascular endothelial growth factor receptor-1; Ang-1: angiopoietin-1; BPD: bronchopulmonary dysplasia; AOE - antioxidant enzyme activity; ETC - electron transport chain; PTP: permeability transition pore (copyright - Vasantha HS Kumar, MD)

ethnicity [46], and this may be related to the protective effects of sex hormones in females [46]. Induction of HIF- $2 \alpha$ and ANG1 may play an essential role in microvascular stability and vascular remodeling. Caffeine-induced endothelial-dependent relaxation mediated by nitric oxide, endothelial-independent relaxation mediated by phosphodiesterase inhibition [47] and adenosine receptor blockade [15] among other smooth muscle effects [33] is additional contributors to the beneficial effects of caffeine on the vascular smooth muscle.

Improvements in lung morphometry measurements, including secondary septal length, indicate the protective effect of neonatal caffeine administration on postnatal lung growth in mice exposed to hyperoxia in both male and female mice. Caffeine may modulate the dynamic interrelationships between VEGF and ANG1, two critical regulators of pulmonary vascular development early in the evolution of lung injury, contributing to improved alveolarization in adult mice. However, the protective effects of caffeine on alveolar development are debatable with several studies suggesting an adverse effect on alveolar development [10, 14] and others signifying beneficial effects $[12,13,48]$. Even though inflammatory cytokines studied in the lung were unremarkable, caffeine may either worsen inflammation by increasing neutrophil chemoattractant, CXCL-1 [14] or may have a protective effect on lung inflammation [11, 13]. An increase in eNOS activity and tetrahydrobiopterin levels may contribute to improved alveolar structure and angiogenesis in immature lungs [48]. Improvements in lung structure relating to alveolar growth and attenuation of vascular remodeling may add to higher body weight, especially in adult male mice following hyperoxia. However, programming of offspring towards excess growth may occur from alterations in the hypothalamic-pituitary-adrenocortical axis [49] or changes in adenosine receptor expression [50] that play a key role in growth and development following prenatal caffeine [51].

Caffeine may affect multiple pathways and gene expression, and the limitation of the study is its focus on angiogenesis and lung development. Results of protein and mRNA expression of HIF-1 and angiogenic genes following hyperoxia may be difficult to extrapolate to lung growth at 12 weeks of age. Also, as lung growth and gene expression are developmentally regulated, assessment at transitional time points would have been useful. Beneficial effects of caffeine on the pulmonary 
vasculature could not be confirmed by either pulmonary hemodynamic studies or heart remodeling indices. Caffeine acts on tissues everywhere in the body by inhibiting the adenine receptors and increases the respiratory drive, respiratory rate, diaphragm function, and diuresis, among other effects [52, 53]. Postnatal caffeine treatment improves pulmonary function in mid-childhood [54]. We did not assess the impact of caffeine on lung function. Caffeine dose of $20 \mathrm{mg} / \mathrm{kg}$ in mice is equivalent to $2.4 \mathrm{mg} / \mathrm{kg}$ in humans [55]. The treatment administered is well below the recommended dose of $20 \mathrm{mg} / \mathrm{kg}$ loading dose followed by $5-10 \mathrm{mg} / \mathrm{kg}$ as a maintenance dose in neonates for apnea of prematurity [5]. Most of the animal studies with caffeine have used doses similar to ours for more extended periods (10-21 days). Caffeine for 4 days is the shortest duration of administration for assessment of lung histology and morphometry. Despite low dosage of caffeine, we demonstrate beneficial effects on angiogenesis, alveolarization, and vascular remodeling in adult mice. Even small doses of postnatal caffeine may have beneficial effects on lung growth and function over long-term with benefits apparent in male mice.

Caffeine is extensively used in premature neonates in the treatment of apnea of prematurity and to decrease the incidence of BPD. Although administered in large doses for long periods in newborns, the toxic effects of caffeine are infrequent. We have reported the beneficial effects of postnatal caffeine on lung morphometry and microvascular development with the potential to attenuate pulmonary vascular remodeling in male mice. Caffeine may modulate HIF-induced angiogenesis in mice exposed to hyperoxia, contributing to improved lung growth in adult mice.

\footnotetext{
Abbreviations

ANG1: Angiopoietin-1; BPD: Bronchopulmonary dysplasia; ELISA: Enzymelinked immunosorbent assay; eNOS: Endothelial nitric oxide synthase; HIF: Hypoxia-inducible factor; HPF: High power field; IL6: Interleukin-6; INF$\gamma$ : interferon $\gamma$; PCR: Polymerase chain reaction; PHD-2: Prolyl hydroxylase-2; RA: Room air; RAC: Radial alveolar count; TGF- $\beta$ : Transforming growth factorB; TNF-a: Tumor necrosis factor a; VEGF: Vascular endothelial growth factor; VEGFR1/FLT1: Vascular endothelial growth factor receptor-1; VLBW: Very low birth weight
}

\section{Acknowledgments}

Not applicable

\section{Authors' contributions}

VD and VK conceived and designed the study. HW and VD were responsible for breeding, mice experiments \& immunohistochemistry; LN performed gene expression, protein, and cytokine analysis; VK supervised the study; VD drafted the initial manuscript; VK revised the manuscript. All authors read and approved the final manuscript.

\section{Funding}

The study was supported in part by Marshall Klaus Grant from the American Academy of Pediatrics to Vikramaditya Dumpa (VD), Department of Pediatrics, University at Buffalo, Buffalo, NY.

\section{Availability of data and materials}

The datasets used and analyzed during the current study are available from the corresponding author on reasonable request.

Ethics approval and consent to participate

The study approved by the Institutional Animal Care and Use Committee of the University at Buffalo, Buffalo, NY (IACUC\#PED24116N).

\section{Consent for publication}

Not applicable (animal study)

\section{Competing interests}

The authors declare that they have no competing interests.

\section{Author details}

${ }^{1}$ Winthrop University Hospital, Mineola, NY, USA. ${ }^{2}$ Division of Neonatology, Department of Pediatrics, John R Oishei Children's Hospital, University at Buffalo, 1001 5th Floor Main Street, Buffalo, NY 14203, USA

Received: 22 September 2018 Accepted: 23 July 2019

Published online: 30 July 2019

References

1. Jobe AH. The new bronchopulmonary dysplasia. Curr Opin Pediatr. 2011;23(2):167-72

2. Thebaud B, Abman SH. Bronchopulmonary dysplasia: where have all the vessels gone? Roles of angiogenic growth factors in chronic lung disease. Am J Respir Crit Care Med. 2007;175(10):978-85.

3. Anderson PJ, Doyle LW. Neurodevelopmental outcome of bronchopulmonary dysplasia. Semin Perinatol. 2006;30(4):227-32.

4. Greenough A. Long-term pulmonary outcome in the preterm infant. Neonatology. 2008;93(4):324-7.

5. Schmidt B, Roberts RS, Davis P, Doyle LW, Barrington KJ, Ohlsson A, et al. Caffeine therapy for apnea of prematurity. N Engl J Med. 2006:354(20):2112-21.

6. Schmidt B, Roberts RS, Davis P, Doyle LW, Barrington KJ, Ohlsson A, et al. Long-term effects of caffeine therapy for apnea of prematurity. N Engl J Med. 2007;357(19):1893-902.

7. Schmidt B, Anderson PJ, Doyle LW, Dewey D, Grunau RE, Asztalos EV, et al. Survival without disability to age 5 years after neonatal caffeine therapy for apnea of prematurity. JAMA. 2012;307(3):275-82.

8. Rhein LM, Dobson NR, Darnall RA, Corwin MJ, Heeren TC, Poets CF, et al. Effects of caffeine on intermittent hypoxia in infants born prematurely: a randomized clinical trial. JAMA Pediatr. 2014

9. Doyle LW, Ranganathan S, Cheong JLY. Neonatal caffeine treatment and respiratory function at 11 years in children $<1251 \mathrm{~g}$ birth weight. Am J Respir Crit Care Med. 2017

10. Rath P, Nardiello C, Surate Solalique DE, Agius R, Mizikova I, Huhn S, et al. Caffeine administration modulates TGF-beta signaling but does not attenuate blunted alveolarization in a hyperoxia-based mouse model of bronchopulmonary dysplasia. Pediatr Res. 2017;81(5):795-805.

11. Weichelt U, Cay R, Schmitz T, Strauss E, Sifringer M, Buhrer C, et al. Prevention of hyperoxia-mediated pulmonary inflammation in neonatal rats by caffeine. Eur Respir J. 2013:41(4):966-73.

12. Teng RJ, Jing $X$, Michalkiewicz T, Afolayan AJ, Wu TJ, Konduri GG. Attenuation of endoplasmic reticulum stress by caffeine ameliorates hyperoxia-induced lung injury. Am J Physiol Lung Cell Mol Physiol. 2017; 312(5):L586-L98

13. Nagatomo T, Jimenez J, Richter J, De Baere S, Vanoirbeek J, Naulaers G, et al. Caffeine prevents Hyperoxia-induced functional and structural lung damage in preterm rabbits. Neonatology. 2016;109(4):274-81.

14. Dayanim S, Lopez B, Maisonet TM, Grewal S, Londhe VA. Caffeine induces alveolar apoptosis in the hyperoxia-exposed developing mouse lung. Pediatr Res. 2014;75(3):395-402

15. Fredholm BB, IJzerman AP, Jacobson KA, Klotz KN, Linden J. International Union of Pharmacology. XXV. Nomenclature and classification of adenosine receptors. Pharmacol Rev. 2001;53(4):527-52.

16. Feoktistov I, Goldstein AE, Ryzhov S, Zeng D, Belardinelli L, VoynoYasenetskaya $T$, et al. Differential expression of adenosine receptors in human endothelial cells: role of $\mathrm{A} 2 \mathrm{~B}$ receptors in angiogenic factor regulation. Circ Res. 2002;90(5):531-8. 
17. Feoktistov I, Ryzhov S, Goldstein AE, Biaggioni I. Mast cell-mediated stimulation of angiogenesis: cooperative interaction between $A 2 B$ and $A 3$ adenosine receptors. Circ Res. 2003;92(5):485-92.

18. Ouyang X, Ghani A, Malik A, Wilder T, Colegio OR, Flavell RA, et al. Adenosine is required for sustained inflammasome activation via the a (2) a receptor and the HIF-1alpha pathway. Nat Commun. 2013:4:2909.

19. Merighi S, Benini A, Mirandola P, Gessi S, Varani K, Simioni C, et al. Caffeine inhibits adenosine-induced accumulation of hypoxia-inducible factor1alpha, vascular endothelial growth factor, and interleukin-8 expression in hypoxic human colon cancer cells. Mol Pharmacol. 2007;72(2):395-406.

20. Jakkula M, Le Cras TD, Gebb S, Hirth KP, Tuder RM, Voelkel NF, et al. Inhibition of angiogenesis decreases alveolarization in the developing rat lung. Am J Physiol Lung Cell Mol Physiol. 2000;279(3):L600-7.

21. McGrath-Morrow SA, Cho C, Cho C, Zhen L, Hicklin DJ, Tuder RM. Vascular endothelial growth factor receptor 2 blockade disrupts postnatal lung development. Am J Respir Cell Mol Biol. 2005;32(5):420-7.

22. Forsythe JA, Jiang BH, lyer NV, Agani F, Leung SW, Koos RD, et al. Activation of vascular endothelial growth factor gene transcription by hypoxiainducible factor 1. Mol Cell Biol. 1996;16(9):4604-13.

23. Hato T, Kimura Y, Morisada T, Koh GY, Miyata K, Tabata M, et al. Angiopoietins contribute to lung development by regulating pulmonary vascular network formation. Biochem Biophys Res Commun. 2009;381(2): 218-23.

24. Yu AY, Frid MG, Shimoda LA, Wiener CM, Stenmark K, Semenza GL. Temporal, spatial, and oxygen-regulated expression of hypoxia-inducible factor-1 in the lung. Am J Phys. 1998;275(4 Pt 1):L818-26.

25. O'Reilly MA, Marr SH, Yee M, McGrath-Morrow SA, Lawrence BP. Neonatal hyperoxia enhances the inflammatory response in adult mice infected with influenza a virus. Am J Respir Crit Care Med. 2008;177(10):1103-10.

26. Emery $J \mathrm{~L}$, Mithal $\mathrm{A}$. The number of alveoli in the terminal respiratory unit of man during late intrauterine life and childhood. Arch Dis Child. 1960;35: 544-7.

27. Knudsen L, Weibel ER, Gundersen HJ, Weinstein FV, Ochs M. Assessment of air space size characteristics by intercept (chord) measurement: an accurate and efficient stereological approach. J Appl Physiol. 2010;108(2):412-21.

28. Datta A, Kim GA, Taylor JM, Gugino SF, Farrow KN, Schumacker PT, et al. Mouse lung development and NOX1 induction during hyperoxia are developmentally regulated and mitochondrial ROS dependent. Am J Physiol Lung Cell Mol Physiol. 2015;309(4):L369-77.

29. Nicola T, Hagood JS, James ML, Macewen MW, Williams TA, Hewitt MM, et al. Loss of Thy- 1 inhibits alveolar development in the newborn mouse lung. Am J Physiol Lung Cell Mol Physiol. 2009;296(5):L738-50.

30. Kumar VH, Lakshminrusimha S, Kishkurno S, Paturi BS, Gugino SF, Nielsen L, et al. Neonatal hyperoxia increases airway reactivity and inflammation in adult mice. Pediatr Pulmonol. 2016:51(11):1131-41.

31. Umemura T, Ueda K, Nishioka K, Hidaka T, Takemoto H, Nakamura S, et al. Effects of acute administration of caffeine on vascular function. Am J Cardiol. 2006;98(11):1538-41.

32. Zucchi $\mathrm{R}$, Ronca-Testoni $\mathrm{S}$. The sarcoplasmic reticulum Ca2+ channel/ ryanodine receptor: modulation by endogenous effectors, drugs and disease states. Pharmacol Rev. 1997:49(1):1-51.

33. Echeverri D, Montes FR, Cabrera M, Galan A, Prieto A. Caffeine's vascular mechanisms of action. Int J Vasc Med. 2010;2010:834060

34. Qutub AA, Popel AS. Reactive oxygen species regulate hypoxia-inducible factor 1alpha differentially in cancer and ischemia. Mol Cell Biol. 2008;28(16): 5106-19.

35. Movafagh S, Crook S, Vo K. Regulation of hypoxia-inducible factor-1a by reactive oxygen species: new developments in an old debate. J Cell Biochem. 2015;116(5):696-703.

36. Benderro GF, Sun X, Kuang Y, Lamanna JC. Decreased VEGF expression and microvascular density, but increased HIF-1 and 2alpha accumulation and EPO expression in chronic moderate hyperoxia in the mouse brain. Brain Res. 2012;1471:46-55.

37. Terraneo L, Virgili E, Caretti A, Bianciardi P, Samaja M. In vivo hyperoxia induces hypoxia-inducible factor-1alpha overexpression in LNCaP tumors without affecting the tumor growth rate. Int J Biochem Cell Biol. 2014;51: 65-74.

38. Kakio S, Funakoshi-Tago M, Kobata K, Tamura H. Coffee induces vascular endothelial growth factor (VEGF) expression in human neuroblastoma SHSY5Y cells. Nutr Neurosci. 2017:20(6):336-42.
39. Gygi SP, Rochon Y, Franza BR, Aebersold R. Correlation between protein and mRNA abundance in yeast. Mol Cell Biol. 1999;19(3):1720-30.

40. Hosford GE, Olson DM. Effects of hyperoxia on VEGF, its receptors, and HIF2alpha in the newborn rat lung. Am J Physiol Lung Cell Mol Physiol. 2003; 285(1):L161-8.

41. Maniscalco WM, Watkins RH, D'Angio CT, Ryan RM. Hyperoxic injury decreases alveolar epithelial cell expression of vascular endothelial growth factor (VEGF) in neonatal rabbit lung. Am J Respir Cell Mol Biol. 1997;16(5): 557-67.

42. Maniscalco WM, Watkins RH, Roper JM, Staversky R, O'Reilly MA. Hyperoxic ventilated premature baboons have increased p53, oxidant DNA damage and decreased VEGF expression. Pediatr Res. 2005;58(3):549-56.

43. Asikainen TM, Schneider BK, Waleh NS, Clyman Rl, Ho WB, Flippin LA, et al. Activation of hypoxia-inducible factors in hyperoxia through prolyl 4hydroxylase blockade in cells and explants of primate lung. Proc Natl Acad Sci U S A. 2005;102(29):10212-7.

44. Buczynski BW, Maduekwe ET, O'Reilly MA. The role of hyperoxia in the pathogenesis of experimental BPD. Semin Perinatol. 2013;37(2):69-78.

45. Kumar VHS, Wang H, Kishkurno S, Paturi BS, Nielsen L. Ryan RM. Anat Rec (Hoboken): Long-Term Effects of Neonatal Hyperoxia in Adult Mice; 2017.

46. Sandberg $\mathrm{K}, \mathrm{Ji}$ H. Sex differences in primary hypertension. Biol Sex Differ. 2012;3(1):7.

47. Hatano Y, Mizumoto K, Yoshiyama T, Yamamoto M, Iranami H. Endotheliumdependent and -independent vasodilation of isolated rat aorta induced by caffeine. Am J Phys. 1995;269(5 Pt 2):H1679-84.

48. Jing X, Huang YW, Jarzembowski J, Shi Y, Konduri GG, Teng RJ. Caffeine ameliorates hyperoxia-induced lung injury by protecting $\mathrm{GCH} 1$ function in neonatal rat pups. Pediatr Res. 2017;82(3):483-9.

49. Xu D, Zhang B, Liang G, Ping J, Kou H, Li X, et al. Caffeine-induced activated glucocorticoid metabolism in the hippocampus causes hypothalamicpituitary-adrenal axis inhibition in fetal rats. PLoS One. 2012;7(9):e44497.

50. Rivkees SA, Wendler CC. Adverse and protective influences of adenosine on the newborn and embryo: implications for preterm white matter injury and embryo protection. Pediatr Res. 2011;69(4):271-8.

51. Papadopoulou E, Botton J, Brantsaeter AL, Haugen M, Alexander J, Meltzer $\mathrm{HM}$, et al. Maternal caffeine intake during pregnancy and childhood growth and overweight: results from a large Norwegian prospective observational cohort study. BMJ Open. 2018;8(3):e018895.

52. Dekker J, Hooper SB, van Vonderen JJ, Witlox R, Lopriore E, Te Pas AB. Caffeine to improve breathing effort of preterm infants at birth: a randomized controlled trial. Pediatr Res. 2017;82(2):290-6.

53. Kraaijenga JV, Hutten GJ, de Jongh FH, van Kaam AH. The effect of caffeine on diaphragmatic activity and tidal volume in preterm infants. J Pediatr. 2015;167(1):70-5.

54. Doyle LW, Ranganathan S, Cheong JLY. Neonatal caffeine treatment and respiratory function at 11 years in children under 1,251 g at birth. Am J Respir Crit Care Med. 2017;196(10):1318-24.

55. Reagan-Shaw S, Nihal M, Ahmad N. Dose translation from animal to human studies revisited. FASEB J. 2008;22(3):659-61.

\section{Publisher's Note}

Springer Nature remains neutral with regard to jurisdictional claims in published maps and institutional affiliations.

Ready to submit your research? Choose BMC and benefit from

- fast, convenient online submission

- thorough peer review by experienced researchers in your field

- rapid publication on acceptance

- support for research data, including large and complex data types

- gold Open Access which fosters wider collaboration and increased citations

- maximum visibility for your research: over $100 \mathrm{M}$ website views per year

At BMC, research is always in progress.

Learn more biomedcentral.com/submissions 